LA INVENCIÓN DEL PATRIMONIO NATURAL EN ESPAÑA. POLÍTICA, ACADEMIA, ACTIVISMO Y COMUNICACIÓN /

THE INVENTION OF NATURAL HERITAGE IN SPAIN. POLITICS, ACADEMY, ACTIVISM AND COMMUNICATION

\section{ACTIVISMO MEDIOAMBIENTAL EN LA ÉPOCA TARDOFRANQUISTA. EL CASO DE EL SALER}

\author{
Sarah Hamilton \\ Auburn University (Auburn, Alabama, EE.UU.) \\ srhamilton@auburn.edu
}

Cómo citar este artículo/Citation: Hamilton, S. (2016). Activismo medioambiental en la época tardofranquista. El caso de El Saler. Arbor, 192 (781): a346. doi: http://dx.doi. org/10.3989/arbor.2016.781n5004

Recibido: 25 febrero 2015. Aceptado: 09 octubre 2015.

RESUMEN: Este artículo traza la evolución de las ideas y el discurso ambientalista durante las últimas décadas del régimen de Franco, entre 1950 y 1975. A lo largo de este período, un grupo de naturalistas y científicos naturales colaboraron con oficiales del régimen y una red conservacionista internacional para proteger espacios concretos de especial valor ecológico. A fines de la década de 1960, a medida que el régimen se debilitaba y el descontento social crecía, apareció un nuevo grupo de activistas que veían la protección ambiental como inseparable de los problemas de justicia social. A través del análisis de la campaña antidesarrollista a propósito de los alrededores de la Albufera en Valencia, este artículo estudia las tensiones entre estas corrientes que convivieron en los orígenes del movimiento medioambiental en España así como el papel del activismo medioambiental en la erosión de la legitimidad política del régimen.

PALABRAS CLAVE: conservación; ecologismo; activismo; Franco; dictadura; Valencia.

\section{ENVIRONMENTAL ACTIVISM IN THE LATE FRANCO YEARS. THE CASE OF EL SALER}

Copyright: (C) 2016 CSIC. Este es un artículo de acceso abierto distribuido bajo los términos de la licencia Creative Commons Attribution (CC BY) España 3.0.
ABSTRACT: This article provides an overview of the evolution of environmental ideas and discourse during the final decades of the Franco regime, between 1950 and 1975. Throughout this period, a group of naturalists and natural scientists worked in collaboration with regime officials and an international network of conservationists to protect discrete spaces with special ecological value. By the late 1960s, as the regime weakened and social unrest increased, a new group of activists emerged who understood environmental protection as inextricably linked to issues of social justice. Through an analysis of an antidevelopment campaign carried out in the area surrounding the Albufera de Valencia, this article examines the tensions between these currents in the origins of the Spanish environmental movement, and the role of environmental activism in the erosion of the dictatorship's political legitimacy.

KEYWORDS: conservation; environmentalism; activism; Franco; dictatorship; Valencia. 


\section{LA EVOLUCIÓN DEL PENSAMIENTO MEDIOAMBIENTAL}

El movimiento medioambiental español del siglo $\mathrm{XX}$, como los de otros países occidentales, ha tomado una amplia variedad de formas, desde los esfuerzos de científicos respetados para proteger espacios concretos a la protesta abierta de una juventud radicalizada. Incluso bajo el régimen franquista de los cincuenta, cuando se frustraban casi todos los esfuerzos civiles por oponerse a la política oficial, un grupo reducido de españoles dio a conocer sus preocupaciones sobre la degradación del medio físico del país, y dirigiendo sus esfuerzos a la conservación de ecosistemas únicos y lugares icónicos como Doñana. Pero a finales de la década de 1960, una nueva ola de ciudadanos aprovechó el espacio forjado por los conservacionistas para ocuparse de una amplia gama de causas sociales, redefiniendo el estado del medio ambiente como un factor entre muchos que contribuían al bienestar humano. Durante la década final de la dictadura, las corrientes paralelas de ecologismo y conservacionismo formaron las bases ideológicas de un movimiento desorganizado y heterogéneo.

En su monografía seminal, Forcing the Spring, Robert Gottlieb exploró la intersección entre justicia social y justicia ambiental, una intersección complicada por el hecho de que los activistas de base de la justicia social no suelen identificarse con las cuestiones ambientales (Gottlieb, 2005). Cuestiones tales como la extensión urbana, la calidad de agua y aire, y el acceso a parques e instalaciones de recreación, por citar solo los más evidentes, ofrecen terreno común para los residentes urbanos de la clase trabajadora y las élites intelectuales que se encuentran en grupos abiertamente ecologistas. En el caso de la España franquista, el vocabulario de un tercer grupo, los conservacionistas, derivado de un interés en la gestión guiada por la pericia científica, servía para dar cobertura política a las agendas socio-políticas de los otros dos.

La Dehesa de El Saler, un parque popular en la costa de Valencia y sujeto de uno de los grandes planes urbanísticos apoyados por el régimen entre 1964 y 1973, fue también el lugar de una de las primeras campañas ecologistas organizadas en España. Ocho años antes de que los activistas más prominentes del país firmaran el Manifiesto de Benidorm, un grupo de vecinos, periodistas y profesores de la ciudad de Valencia pusieron a prueba estrategias e ideas que juntaron la pericia científica y los conceptos tradicionales sobre el valor del medio ambiente con una nueva conciencia social. Aunque Valencia no pretende representar una norma nacional, este caso es uno de los mejor conocidos del activismo ambiental temprano y remueve muchas de las tendencias generales de la época. Preocupaciones populares sobre la calidad de vida urbana, intereses de personas pertenecientes a todo el espectro político sobre los paisajes únicos del país, y críticas políticas marxistas contra el régimen franquista y el sistema capitalista industrial confluyeron, transformando el intento de proteger un parque local en una protesta generalizada contra la privatización, un ataque contra la corrupción e incompetencia política, y una salida para las frustraciones con el statu quo político y social. Como estudio de caso, El Saler sugiere que el paisaje y el medio ambiente desempeñaron papeles críticos en la creación de un espacio social para la protesta durante la época tardofranquista, no solo por los orígenes complicados del ambientalismo de posguerra en España, sino también por la importancia que los espacios físicos concretos tuvieron en labrar identidades regionales.

El análisis conocido de Samuel Hays sobre el pensamiento medioambiental en los Estados Unidos durante el siglo XX resuena claramente en el contexto español. El concepto de "conservación," con orígenes en la política progresista de Gifford Pinchot y Theodore Roosevelt, escribe Hays, era fundamentalmente una estrategia para el uso sostenible de recursos naturales en la que la explotación y producción a largo plazo estaban aseguradas a través de prácticas basadas en la gestión científica. Aunque los conservacionistas a menudo entraban en conflicto con los defensores de la preservación de paisajes silvestres, los preservacionistas y conservacionistas compartían una filosofía generalmente compatible que reconocía una clara división entre el mundo natural y el mundo social. En la práctica, permitían la continua expansión del desarrollo industrial, con la reserva de espacios y especies particulares como sacrosantos, principalmente en la forma de Parques Nacionales (Hays, 1959).

Los cambios culturales de la época de posguerra mundial dieron origen a una visión radicalmente divergente sobre la relación entre los humanos y la naturaleza. En los 60 y a principios de los 70 , jóvenes del mundo occidental acampaban, hacían senderismo, cultivaban comida ecológica, y "volvían a la naturaleza," juntándose así en una contracultura que desdeñaba el consumo capitalista y abrazaba un entendimiento del bienestar humano y la salud medioambiental como dos caras de una misma moneda. Los Parques Nacionales y zonas silvestres "prístinas" eran iniciativas encomiables, pero los nuevos pensadores vinculaban la degradación del ambiente físico a los 
problemas sociales. Describían la contaminación, el desarrollo y las industrias extractivas como perjudiciales no solamente para la flora y la fauna, sino también para los humanos que habitaban y atravesaban los mismos paisajes.

Michael Bess, escribiendo sobre el caso francés, describe una escisión parecida entre "ecologismo centrado en la naturaleza" (nature-centered environmentalism) más conservador, patrocinado por los científicos y naturalistas, quienes consideran que los ecosistemas y paisajes en sí mismos son objetos de valor que demandan protección frente a los abusos humanos, y el "ecologismo social" (social environmentalism), territorio de progresistas y urbanitas quienes comprenden la naturaleza como espacio social, intrínsecamente enlazado con la vida cotidiana de los humanos (Bess, 2003).

El caso español refleja las mismas tensiones y colaboraciones entre estas corrientes ideológicas, pero dentro del contexto de la época tardofranquista el ecologismo asumía dimensiones políticas adicionales. El ambientalismo centrado en la naturaleza apareció entre algunos científicos naturales de España al principio de la década de 1950, cuando por fin la economía nacional empezó a recuperarse de los estragos de la Guerra Civil. Algunos de los ingenieros de montes que llevaron a cabo la trasformación del paisaje a través de proyectos hidrológicos, la exterminación de "alimañas" y la repoblación forestal, dieron a conocer su preocupación sobre los efectos a largo plazo de los programas ambiciosos del Estado (Farias Barona, 1942; Alonso-Geta, 1962). A la vez, algunos biólogos y ornitólogos, alarmados por la amenaza que presentaba el desarrollo, que llegaba hasta las zonas más silvestres y remotas, se hicieron eco de estas preocupaciones en cartas a sus colegas dentro de la Administración, especialmente a los funcionarios del Consejo Superior de Investigaciones Científicas (CSIC). En el CSIC encontraron algunos aliados simpatizantes y lograron varios éxitos en sus esfuerzos por proteger varios rincones del territorio nacional.

Probablemente la campaña más significativa fue el rescate del Coto de Doñana de su destino como plantación de eucalipto y guayule, tal como describe Lino Camprubí en otro capítulo de este volumen. La reserva abarcaba menos de la mitad de las tierras que los ornitólogos esperaba adquirir, pero tuvo un papel simbólico importante como primer logro concreto de una alianza conservacionista internacional (Valverde, 1975).
La campaña de Doñana, junto con otros esfuerzos para proteger paisajes de valor ecológico, tuvo éxito en gran parte por la disposición de los conservacionistas a cooperar con la Administración de Franco. Aunque la etapa más sangrienta de la represión franquista había acabado en 1945, la Guardia Civil todavía detenía, torturaba e intimidaba a quienes abiertamente dieran voz a la oposición política al régimen. Los naturalistas que propugnaban la preservación de los paisajes españoles, por tanto, lo hacían dentro de un espacio apolítico, forjado con cuidado dentro del contexto de represión cotidiana. Condenas generales sobre los esfuerzos del régimen por ampliar la producción, por ejemplo, no habrían sido toleradas. En cambio, llamadas de preservar paisajes estéticamente espectaculares, ecológicamente únicos, o culturalmente icónicos como objetos de orgullo y patrimonio nacional recibían una cálida recepción por parte del régimen nacionalista. Cartas redactadas con cuidado, enlaces estrechos con particulares dentro de las salas de poder, y esfuerzos concienzudos para presentar la conservación como un deber patriótico y basado en la ciencia permitían a los conservacionistas españoles, tal como a sus homólogos en otros países autoritarios, lograr una serie de victorias menores en la preservación de espacios pequeños y discretos.

Una interpretación de todo esto es que algunos científicos realizaron una forma de oposición en clave, una forma de "vivir en la verdad" que ha sido observada en otras sociedades autocráticas del siglo XX (Havel y Keane, 1985). Denuncias parecidas, poco destacadas y de baja intensidad, constituían uno de los canales más característicos para expresar la inquietud política en la primera época del franquismo. Esta forma de disidencia era una manera de bajo coste de mostrar la disconformidad y reflejaba la muy limitada esfera para la expresión cautelosa de opiniones divergentes bajo una dictadura. Al afirmar un conjunto de hechos ostensiblemente imparciales, basados en la experiencia científica, los científicos naturales desafiaban la narrativa dominante de progreso y desarrollo que el Estado patrocinaba.

Sin embargo, otra interpretación, que quizás sea compatible con la primera, es que el movimiento de "ecologismo centrado en la naturaleza" en España fue esencialmente conservador. Esta interpretación se respalda no solo por los objetivos relativamente modestos de sus campañas, sino también por la involucración de pilares de la sociedad elitista, sobre todo del mundo financiero y político. Algunos miembros de la Sociedad Española de Ornitología (SEO) ejercían 
también como directores de bancos y funcionarios de alto rango, y cazaban con políticos franquistas, con quienes después degustaban las piezas. Entre ellos, los científicos pertenecían a aquellos intelectuales españoles que no habían huido del país ni perdido sus puestos en la represión franquista. El ornitólogo José Antonio Valverde expresamente elogió el interés del régimen por la naturaleza, escribiendo en el año que murió Franco que "fue el Caudillo quien personalmente tomó la decisión de ordenar la creación del Parque Nacional de Doñana", mientras "el Ministro de Turismo, don Manuel Fraga, y el Ministro de Agricultura hicieron un trabajo espléndido" con el proceso (Valverde, 1975, p. 45). Al centrarse exclusivamente sobre paisajes aislados, dejando a un lado los problemas más sistémicos que formaban la base de las tendencias nacionales de desarrollo y urbanización, los conservacionistas generaban la impresión de que los problemas se podían solucionar con la recaudación de fondos o cambios sencillos a planes concretos. No hacía falta desafiar las políticas subyacentes, ni rectificar la falta de regulación sobre la contaminación y ordenación del territorio. Vale la pena notar, también, que los paisajes elegidos para su protección yacían en tierras no productivas; ni siquiera el entusiasmo de Franco hacia las presas y la repoblación habrían podido hacerlas rentables. De los cinco Parques Nacionales declarados por Franco durante la década de 1950, por ejemplo, tres se encontraban en paisajes alpinos, mientras Doñana y las Tablas de Daimiel, dos zonas de gran valor faunístico, se ubicaban en tierras húmedas y remotas con potencial económico limitado. Pastizales, bosques y zonas costeras, sitios de alto potencial para el desarrollo económico, brillaron por su ausencia en esta corta lista.

La figura más destacada en la historia del ecologismo español, Félix Rodríguez de la Fuente, compartía este territorio político ambiguo con los conservacionistas. A través de sus programas de radio y televisión, presentaba a muchos españoles los conceptos del equilibrio natural y uso sostenible, explicando la alteración de aquel equilibrio en detrimento del mundo natural que suponían las prácticas de construcción de presas y de exterminación de "alimañas". Estas ideas resonaron en la generación joven que, como en otros países occidentales, estaba predispuesta al escepticismo hacia los esquemas tecnocráticos y los valores industrial-capitalistas.

Pero aunque muchos de los que veían los programas del "Amigo Felix" cuando niños adoptaban políticas ecologistas cuando se hacían mayores, Rodríguez de la Fuente nunca atribuía el deterioro del medio ambiente abiertamente a las políticas del Estado franquista. Como los progresistas estadounidenses de las décadas anteriores, promocionaba prácticas de gestión informadas por la ciencia que permitirían la convivencia de las industrias extractivas, por un lado, y la salud medioambiental por otro. Criticaba, por ejemplo, el rechazo por parte de los ingenieros de la experiencia ofrecida por expertos en las ciencias naturales, y en particular de sus advertencias sobre las consecuencias imprevistas del desarrollo para los paisajes y ecosistemas, pero mantenía el silencio sobre las premisas fundamentales de la ingeniería hidrológica. Por una parte, este era un resultado del pragmatismo: el apoyo y patrocinio del Estado español eran necesarios para continuar la radiodifusión de sus programas, hecho que sin duda tenía influencia sobre su decisión de mantenerse al margen de los debates sobre las políticas estatales y centrarse en los paisajes específicos y contaminadores puntuales $u$ otros agentes de bajo nivel del cambio ecológico. Por la otra, su postura apolítica permitía que su mensaje llegase al público más amplio posible y facilitaba su colaboración con aliados de todo el espectro político. De esta manera, Rodríguez de la Fuente ocupaba un punto medio entre la conservación de la SEO y el ecologismo que estaba por venir.

En 1968, aprovechando el reciente cambio en las leyes de asociaciones cívicas, Rodríguez de la Fuente y algunos compañeros rompieron con la SEO para fundar la Asociación para la Defensa de Naturaleza (Adena), que pronto llegó a ser la delegación española del World Wildlife Fund. Sin embargo, mantenía muchas de las prácticas y políticas conservadoras de su antecesora. Los enlaces estrechos de la organización con las élites del régimen se evidencian por sus colaboradores: de nuevo, la junta directiva de Adena incluía gigantes del mundo financiero como Manuel de Prado y Colón de Carvajal, mientras que el Príncipe Juan Carlos de Borbón aceptó la presidencia honorífica (Fernández, 1999). Por lo tanto, Adena se agregó a una lista creciente de grupos conservacionistas que utilizaban el apoyo de los poderes fácticos para conseguir sus objetivos. La Sociedad Real para la Protección de Aves (Royal Society for the Protection of Birds), fundada en 1889 por aristócratas inglesas lideradas por la duquesa de Portland, no era más que la primera de muchas asociaciones semejantes que contaban con la aprobación oficial de la clase dirigente. En los Estados Unidos, el Club Boone y Crockett (Boone and Crockett Club) del presidente Theodore Roosevelt solicitaba la afiliación de hombres de negocios y "aventureros" de 
las altas esferas de la sociedad americana. La propia $W W F$, la organización madre de Adena, nombró al príncipe Bernardo de Holanda como presidente fundador en 1962, y sus sucesores durante las décadas siguientes incluían un magnate del petróleo, varios líderes de negocios internacionales y varios jefes de Estado. En algunos casos, estas alianzas fueron puramente honoríficas y servían principalmente como sello de aprobación oficial; en otros, la importancia social y política de los miembros de las organizaciones desempeñaba un papel fundamental en la capacidad de éstas para alcanzar sus objetivos.

Pero mientras que la colaboración de los defensores del medio ambiente con los miembros y beneficiarios del sistema capitalista industrial no concordaba con los intereses de la generación contracultural, en el contexto español la disyuntiva se magnificaba por estar el sistema inextricablemente enlazado con un régimen altamente polarizador. Aunque el apoyo de las élites sociales en gran medida posibilitaba el éxito de la conservación en los últimos años de la dictadura, también permitía que el propio régimen hiciera suyas ciertas ideas y terminología del conservacionismo, enemistando al movimiento conservacionista con los progresistas jóvenes. Dada la creciente decrepitud del dictador a partir de 1966, la retórica conservacionista se convirtió en una de las muchas herramientas empleadas por los continuistas dentro del régimen para suavizar la transición política inminente y para equiparar la imagen extranjera de España con los de sus vecinos europeos, donde el ecologismo ya estaba en boga. En la práctica, este conservacionismo generalmente consistía en pintar de verde las prácticas existentes, en lugar de hacer cambios sustanciales en la política. Por lo tanto, la Dirección General de Montes, Caza y Pesca Fluvial cambió su nombre por el del Instituto para la Conservación de la Naturaleza (ICONA) en 1971, con intención de legitimar al régimen a los ojos internacionales. Como patrocinador principal de Rodríguez de la Fuente, el nuevo logotipo de ICONA aparecía prominentemente en el comienzo de todos sus documentales sobre las especies en peligro de extinción y paisajes degradados, mientras los ingenieros forestales del propio ICONA reclamaban humedales y plantaban pinos por todo el país.

A pesar de la popularidad personal de Félix, algunos de entre la generación de activistas progresistas que llegaron a la mayoría de edad en los años del tardofranquismo vieron en la complicidad de Adena con el régimen una grave falla. Demasiado jóvenes para recordar los horrores de la guerra y sus secuelas, y cria- dos con las ventajas y oportunidades educativas que faltaron a sus padres, experimentaban el régimen menos como amenaza verdadera a su seguridad personal que como la manifestación de un sistema socioeconómico y político fundamentalmente injusto. En comparación con la falta de derechos humanos básicos y la supresión de la libertad intelectual, el conservacionismo parecía territorio de "cazadores de mariposas" y viejos de la Universidad, quienes ignoraban la relación compleja entre los mundos sociales y naturales, como quedaba demostrado por su interés limitado a la preservación de lugares silvestres de difícil acceso y su rechazo a la lucha contra las causas principales de la degradación del medio ambiente. En armonía con los teóricos marxistas y contraculturales de popularidad creciente en todo el mundo occidental, los jóvenes activistas españoles entendían las dos cosas - la protección del medio ambiente y el rechazo del régimen - como intrínsecamente vinculadas. El capitalismo industrial y la falta de instituciones democráticas, argumentaban, yacían en el corazón de cada desafío importante al bienestar humano en España ${ }^{1}$.

Este vínculo se encontraba más claramente en las condiciones de vida de la clase obrera. Entre 1960 y 1970, aproximadamente 2,7 millones de españoles se trasladaron desde las zonas rurales a las zonas urbanas, donde se establecieron en barrios sin infraestructuras, poblados por poco más que chabolas y con una carencia de servicios sociales básicos tales como centros de salud, parques, agua limpia, transportes públicos y escuelas (Radcliff, 2011). Mientras Adena se ocupaba de campañas para paliar los efectos del abandono de tierras rurales y la expansión urbana en la flora y la fauna de espacios concretos, la gente trabajadora, y un número creciente de académicos y profesores de las Facultades de Ciencias Sociales, se preocupaban por los impactos de los cambios demográficos y físicos en la población humana.

A partir de 1964, con la relajación de las restricciones legales contra las asambleas, empezaron a surgir asociaciones de vecinos con bases populares. Basadas en los barrios nuevos de las ciudades, demandaban soluciones a la falta de ordenación urbana y, en muchos casos, organizaban sus propios arreglos cuando se enfrentaban a la ausencia de una respuesta oficial. Los temas que motivaban a las asociaciones son familiares para cualquier estudioso de la justicia social: la distribución equitativa de los recursos urbanos; el saneamiento y el agua potable; la seguridad en las calles; y el derecho de los vecinos a tener voz en las asignaciones de uso de las tierras en las que vivían, 
trabajaban y jugaban. Por primera vez desde la Guerra Civil, los gobiernos locales de todo el país recibían peticiones firmadas por cientos de residentes, quejándose de asuntos desde los pasos de peatones peligrosos hasta la baja presión del agua. La mayoría de las asociaciones de vecinos duraban solo el tiempo necesario para resolver un asunto puntual, pero unas pocas se enredaban con luchas relacionadas con cuestiones más de largo plazo, como el desarrollo o la salud pública. Para volar por debajo del radar de la Guardia Civil, que todavía tenía autoridad para perseguir organizaciones con objetivos abiertamente políticos o basados en clases económicas, incluso estas asociaciones más activistas seguían definiéndose por los asuntos locales y no por una agenda anti-régimen en sí (García, 1995; Taylor, 2009; Radcliff, 2011).

Los vecinos, en general, no se identificaban como ecologistas en el mismo sentido en el que, cada vez más, se utilizaba el término en otros países occidentales. Sin embargo, según una definición que abarca toda la diversidad del movimiento actual, sin duda las preocupaciones de las familias urbanas de los 60 y 70 tenían mucho que ver con el medio físico. Escribiendo sobre la ciudad estadounidense a comienzos del siglo pasado, Gottlieb describe: "Ios problemas ambientales de la ciudad industrial - los suministros de agua limitados y contaminados, recolección y eliminación inadecuada de residuos, la mala ventilación y el aire contaminado y lleno de humo, barrios y conventillos superpoblados" como temas clave no solo para los reformadores sociales de la época, sino también para los activistas ambientales contemporáneos (Gottlieb, 2005, p. 90). La salud pública y las condiciones contra las cuales protestaban las asociaciones de vecinos eran producto de las condiciones ambientales.

Pamela Radcliff ha escrito sobre la infiltración de agentes comunistas y socialistas en algunas asociaciones de vecinos, pero el socio medio parece haber sido relativamente apolítico, preocupado principalmente con objetivos concretos de corto plazo y menos interesado en una reforma sistémica (Radcliff, 2011). Sin embargo, un pequeño grupo de intelectuales españoles, procedentes mayoritariamente de las facultades universitarias de Arquitectura, Derecho, Medicina y Sociología, vio una relación entre las organizaciones de bases locales y las corrientes ideológicas contraculturales que circulaban en el extranjero. Este grupo cumplía en las asociaciones de vecinos la misma función que activistas como Jane Addams y Alice Hamilton habían ejercido en las reformas urbanas de la era progresista: en Estados Unidos unían el aprieto de las familias trabajadoras con cuestiones ambientales generalizadas y trabajaban dentro del mundo intelectual para fomentar cambios duraderos. Fuertemente influidos por sus propios viajes fuera de España o por las lecturas clandestinas, desarrollaron una variedad específicamente española de ecologismo que integraba conceptos globales de la ecología con la política nacional progresista, para oponerse a las políticas industrio-capitalistas de productivismo implacable del régimen. El vocabulario del movimiento ecologista internacional mundial les permitía articular conexiones entre los problemas locales concretos y la influencia perdurable del régimen antidemocrático.

Las aspiraciones del movimiento conservacionista sencillamente no bastaban para enfrentarse a las condiciones de vida de la gente trabajadora bajo el sistema capitalista, y hacer la vista gorda con los asuntos sociales para paliar los efectos sobre los "pájaros y árboles" comenzó a verse como un defecto moral. "El conservacionismo nostálgico", escribió Josep-Vicent Marqués, un joven profesor de sociología en la Universidad de Valencia y una de las figuras clave en el nuevo movimiento, aspiraba solamente "a salvar espacios naturales, oasis o guetos más o menos bonitos segregados del entorno humano, que quedaría entregado a una degradación juzgada irreversible" (Marqués, 1980, p. 123). Al contrario, el nuevo ecologismo hundía sus raíces en el deterioro de las condiciones de vida de los trabajadores bajo el sistema capitalista. Por lo tanto, los ecologistas adoptaron las causas invocadas por las asociaciones de vecinos, exigiendo agua y comida sana; barrios y parques ordenados con infraestructura adecuada; y derechos laborales. En la "Propuesta de Daimiel", Marqués y otros activistas establecieron los bases ideológicas del ecologismo como "un movimiento socioeconómico basado en la idea de armonía de la especie humana con su medio, que lucha por una vida lúdica, creativa, igualitaria, pluralista y libre de explotación y basada en la comunicación y la cooperación de las personas" (Federación del Movimiento Ecologista, 1978). Tales retos mezclaban los imperativos sociales del país con las demandas físicas de la biosfera; un medio sano se vio como obligatorio para asegurar que las familias de la clase laboral tuvieran acceso a estos derechos fundamentales (Marqués, 1980).

Aunque fue "lógico que amantes de los pájaros, ambientalistas y ecologistas varios coincidiésemos e incluso luchásemos codo con codo", Marqués y sus colegas declinaron aliarse con los conservacionistas 
que se comprometían con el régimen, la encarnación del sistema capitalista y antidemocrático, a cambio de la protección de unas zonas y especies aisladas (Marqués, 1980). Los conservacionistas, como era de esperar, tenían una perspectiva bastante distinta sobre el tema. Rodríguez de la Fuente, por ejemplo, atribuyó al ecologismo "un papel muy importante y muy positivo", pero sugirió que los activistas nuevos carecían tanto de dedicación a los sistemas naturales como de un correcto entendimiento de los mismos. Entre quienes toman la calle para denunciar la expropiación de un parque, la construcción de una central nuclear, o la contaminación de un río, escribió, "puede haber personas quienes, quizás, al no existir el ecologismo serían activistas de hippies y flores" (Araújo, 1990, p. 95).

Desde luego, perturbar el statu quo y fortalecer el apoyo popular para las reformas democráticas plantando cara al régimen franquista estaban sin duda entre los objetivos de los ecologistas. El propio Marqués demostró poco interés en el ambiente como ecosistema, por lo menos en los años tempranos de su carrera. Con unos amigos de la Universidad y del Partit Socialista Valencià (entre ellos Damiá Mollá, colega en la Facultad de Sociología; y Celia Amoroso, la conocida activista feminista y la futura esposa de Marqués), Marqués organizó un grupo en 1970 que se llamaba Germania Socialista. En una de sus primeras protestas, una noche de 1971, la Germania se colaron en un campo de golf de un Parador recién inaugurado en tierras expropiadas y rociaron el césped con un fuerte herbicida. La operación prosiguió perfectamente hasta que el sistema automático de riegos se encendió, asustando a los saboteadores, quienes creyeron haber sido descubiertos y huyeron, dejando atrás su protesta ambiental. Aunque este tipo de ataques no formó parte habitual de sus protestas, Marqués y otros intelectuales sociales no mantuvieron en secreto que su interés en el medio ambiente era en lo relativo a la salud física y emocional humanas (Fernández, 1999; Mateu y Domínguez, 2011a).

Para los ojos no entrenados y poco sofisticados de la Guardia Civil, las diferencias aparentemente obvias entre los ecologistas y los conservacionistas eran a menudo difíciles de detectar. Dado que los grupos de conservación, tales como Adena y la SEO, habían sido totalmente aceptados e integrados en el régimen, los nuevos ecologistas fueron capaces de enmascarar su oposición fundamental al sistema político y económico tras el lenguaje permisible de la salud de los ecosistemas y la conservación del paisaje. Por otra parte, al centrarse en la escala local - tratamiento de agua en un barrio de Madrid, los espacios verdes en el corazón de Barcelona, la contaminación del aire en las afueras de Bilbao - las campañas ambientales se enlazaban con los objetivos legítimos de las asociaciones de vecinos y así evitaban acusaciones de tratar de desestabilizar la política nacional. Por lo menos en cierta medida, por tanto, Rodríguez de la Fuente tenía razón cuando escribió que los ecologistas utilizaron el medio ambiente como tapadera para sus intereses políticos y culturales subyacentes. Esto no quiere decir que los ecologistas en los últimos años de la dictadura no se preocuparan realmente por el mundo natural, ni que sus esfuerzos en campañas concretas no fueran sinceros. Sin embargo, sus palabras y acciones sugieren que las causas y el lenguaje ambientales proveyeron una cubierta conveniente para una agenda más subversiva.

En 1970, Marqués se unió con otros intelectuales activistas de todo el país - tales como Joaquín Araujo, Mario Gaviria, Pedro Costa, Ramón Tamames, José Luis Aranguren, José Vidal-Beneyto, Enrique Borón, y Pablo Castellano - para formar la Asociación Española para la Ordenación del Medio Ambiente (AEORMA) (Fernández, 1999). Más adelante, Costa la llamó “el primer grupo verdaderamente ecologista en la historia del movimiento en España" (Costa Morata, 2011). Durante los siguientes seis años, AEORMA realizó un papel importante en las campañas izquierdistas de todo el país a través de una serie de delegaciones regionales vagamente organizadas. La posición social relativamente alta de sus socios, junto con sus tácticas evasivas y la evitación de la actividad abiertamente política, generalmente protegía AEORMA de represalias oficiales, pero aun así el grupo ocupaba un espacio peligroso intermedio entre la oposición clandestina y las asociaciones de vecinos y grupos conservacionistas legales. $Y$ es que los activistas de AEORMA utilizaron la retórica y tácticas de los grupos legales para perseguir los objetivos de la oposición clandestina. Incluso el nombre del grupo, con su énfasis en la “ordenación," recogía las quejas del movimiento vecinal sobre la falta de planificación del uso de suelo en las ciudades y los suburbios. La agenda de AEORMA no fue ni mucho menos exclusivamente ambiental: incluyó políticas laborales expansivas; la planificación urbana; la educación pública; y la reforma del sistema político, así como los temas más evidentemente ambientales como la contaminación local y la conservación de espacios verdes. Muchas veces, sus actividades combinaban objetivos ambientalistas con otros más políticos, como fue el caso en una de sus primeras campañas nacionales, cuando los activistas salieron al campo para interrumpir una cacería de urogallo. Si 
su objetivo principal era verdaderamente proteger al urogallo, como alegaron a los miembros de la Guardia Civil que acudieron a arrestarlos, o más bien incomodar y molestar a los ministros franquistas distinguidos que participaban en la caza, entre ellos Manuel Fraga, sigue siendo una cuestión abierta (Fernández, 1999; Costa Morata, 2011).

Con Marqués, la delegación regional del País Valenciano de AEORMA contaba con unos cuarenta participantes activos, la mayoría de ellos profesores jóvenes de la Universidad de Valencia, y sus reuniones tenían lugar en un aula de clases en la Facultad de Sociología. Entre ellos se encontraban algunos de los que serían los intelectuales más prominentes de la izquierda valenciana en los años siguientes: Damià Molla, Vicent Soler y Trinidad Simó. Muchos de ellos también se asociaron con la Germania Socialista o el Partit Socialista. Para ellos, la falta de estructura formal y posición cuasi-legal eran atracciones fuertes. "¿Qué era AEORMA?", preguntó en 2011 retóricamente Vicente Gonzales Móstoles, un arquitecto valenciano y ex-socio de AEORMA: "No lo sé. No tuvo dinero, ni estructura, ni dirección, ni organización."2 Otros describen AEORMA como un fantasma; un nombre dado solo para producir la ilusión de que Marqués y otros de los "intelectuales más activos de la Universidad" representaban un grupo más grande que ellos mismos ${ }^{3}$. De hecho, identificar a los "socios" de AEORMA es, en cierta manera, improductivo, dado que ninguna designación como tal existía en su momento. Tal informalidad y falta de fronteras definidas eran, de algún modo, una respuesta a su estado semiclandestino, puesto que la Guardia Civil no podía desmantelar una organización que técnicamente no existía.

La falta de formalidad también ejemplificó la naturaleza juvenil, casi traviesa, de las actividades del grupo, tal como sugieren los episodios como el del campo de golf o la frustración de la cacería de urogallos. Móstoles se rio cuando le enseñé la tapa de un libro compuesto por él hace unos treinta y ocho años, lo que se atribuyó a "AEORMA equipo 3". "iEquipo 3! Aquello fue para la policía", dijo. "Si hay un equipo tres, debe haber unos equipos uno y dos. ilnvestígalo!" (Figura 1).

Tapaderas, disimulo y ocultación fueron sellos del movimiento ecologista en la época tardofranquista, como lo fueron de otros aspectos del activismo democrático ${ }^{4}$. Montones de documentos - artículos de prensa, folletos y comunicados de prensa - implican la existencia de una red compleja y organizada de organizaciones izquierdistas, haciendo causa común entre los
Figura 1. Cubierta del libro publicado por Móstoles y otros activistas ecologistas de Valencia, en la que figura AEORMA Equip 3 como autor.

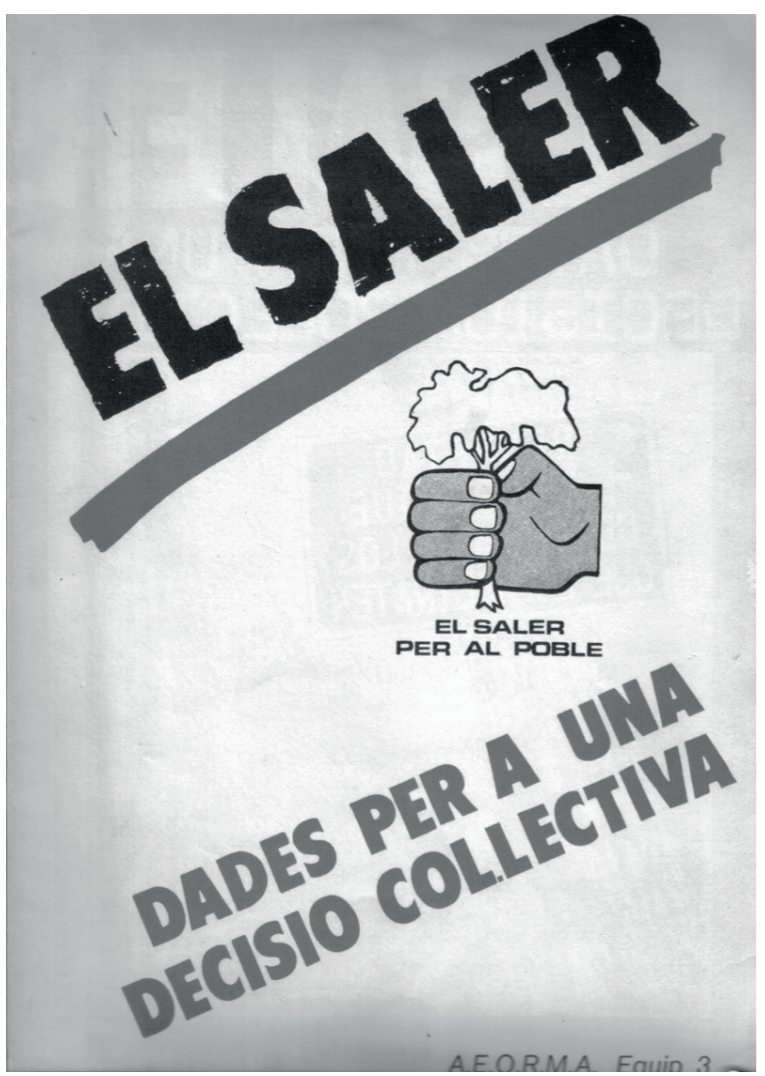

intelectuales valencianos, los socialistas, los comunistas clandestinos, y AEORMA. Tales documentos engañan al investigador, sin embargo, precisamente porque se los diseñaba para engañar. Mientras que las asociaciones laborales se llevaban la peor parte de las represalias del Estado, los opositores intelectuales del régimen utilizaban todo su capital social considerable para confundir a la policía y a los políticos, para crear la ilusión de un levantamiento popular, y para disfrazar sus verdaderos objetivos políticos detrás de una cortina de humo de demandas legales y aparentemente inocuas. Como resultado, muchos de los movimientos inmortalizados en los archivos de hoy se parecen poco a los eventos caóticos e improvisados de la década de 1970.

\section{EL SALER PARA EL PUEBLO}

Todos estos factores - los conflictos y solapamientos entre el conservacionismo y el ecologismo, el legado confuso del activismo tardofranquista y la influencia de una dictadura que se estrellaba en la política local entraron en juego en una campaña valenciana que ha 
venido a conocerse como "El Saler para el Pueblo" (o, más bien, "El Saler per al Poble", como la llamaban los participantes). En términos algo hiperbólicos, el periodista Joaquín Fernández la ha llamado "la movilización ciudadana que posiblemente haya sido más importante en la historia del conservacionismo a favor de un espacio natural", mientras participantes y espectadores lo describen más modestamente como "uno de los primeros movimientos ecologistas" de Europa y por lo tanto, del país (Fernández, 1999, p. 189; Dolç, 2011, p. 10; Mateu y Domínguez, 2011a). Mientras las dos descripciones tienen aspectos verdaderos, la realidad de la campaña de El Saler es mucho más compleja y ejemplifica las incoherencias y conflictos internos de la ideología ecologista a finales del franquismo.

En 1964 el Ayuntamiento valenciano franquista, aprovechando la oleada de turistas extranjeros que acudía a la costa mediterránea, consiguió permiso del Gobierno para emprender un proyecto de construcción inmenso que tendría lugar justo al sur de la ciudad. La Dehesa de El Saler, unos doce kilómetros de playas de arena blanca, bosques umbríos, y atmósfera tranquila a pocos kilómetros del centro urbano, se había mantenido sin desarrollo durante los primeros años del boom turístico. Pertenecía a la ciudad, comprada junto con el Lago de la Albufera adyacente como parque público en 1911 para rescatarla de las amenazas del sector agrario. Durante más de medio siglo, los valencianos ocupaban la Dehesa, según la estación, como zona verde de escape y relajación en las vacaciones y fines de semana. En primavera salían a buscar setas y espárragos en los bosques; en otoño pescaban en el lago o paseaban por las dunas; $y$, por supuesto, en verano, iban miles de valencianos a bañarse en las playas y hacer picnic en la sombra bajo los árboles. Justo al sur de la Dehesa, se alzaban amenazadoras las torres de cemento de Cullera y el desarrollo incontrolado de Perelló, emblemáticos de la nueva etapa de la economía costera. Pero las tierras de la Dehesa habían sido protegidas por una ley que obligaba al Ayuntamiento a "conservar el arbolado de la Dehesa y la integridad de su suelo, el cual no podrá tener otra ocupación o destino agrícola más que el de monte" (Ley cediendo en propiedad al Ayuntamiento de Valencia el lago denominado La Albufera y el monte denominado Dehesa de La Albufera). A cambio de unas tierras de la Dehesa para construir uno de sus queridos paradores, en 1964 Fraga dio permiso al Ayuntamiento para declarar toda la zona como terrenos urbanizables, privatizándolos y excluyendo a la población general de la ciudad.
La urbanización, diseñada por arquitectos y promotores de Madrid, dejaría poco más de dos kilómetros de playa para uso público, mientras las excavadoras aplanarían el resto de la zona, desde las dunas costeras a las marismas estacionales, reemplazándolas con apartamentos de lujo, hoteles de cinco estrellas, y otras instalaciones capaces de albergar una población estacional de 100.000 personas. Mientras que muchos vieron el desarrollo de la Dehesa como preferible a la especulación y falta de ordenación que se estaba produciendo en otros lugares a lo largo del Mediterráneo, el plan de la ciudad, sin embargo, dejó claro que el paisaje se transformaba radicalmente y su función como parque público sería esencialmente eliminada (Figura 2) (Berenguer, 1964; Iglesias, 1970; Ventura, 1970) ${ }^{5}$.

Tan pronto como el Ayuntamiento aprobó el plan, la Real Sociedad Española de Historia Natural, compuesta de científicos respetados de toda España, se puso en contacto con el alcalde de Valencia para hacer

Figura 2. Vistas aéreas del mismo trozo de la Dehesa de EI Saler, antes (1963) y después (1974) de la urbanización.
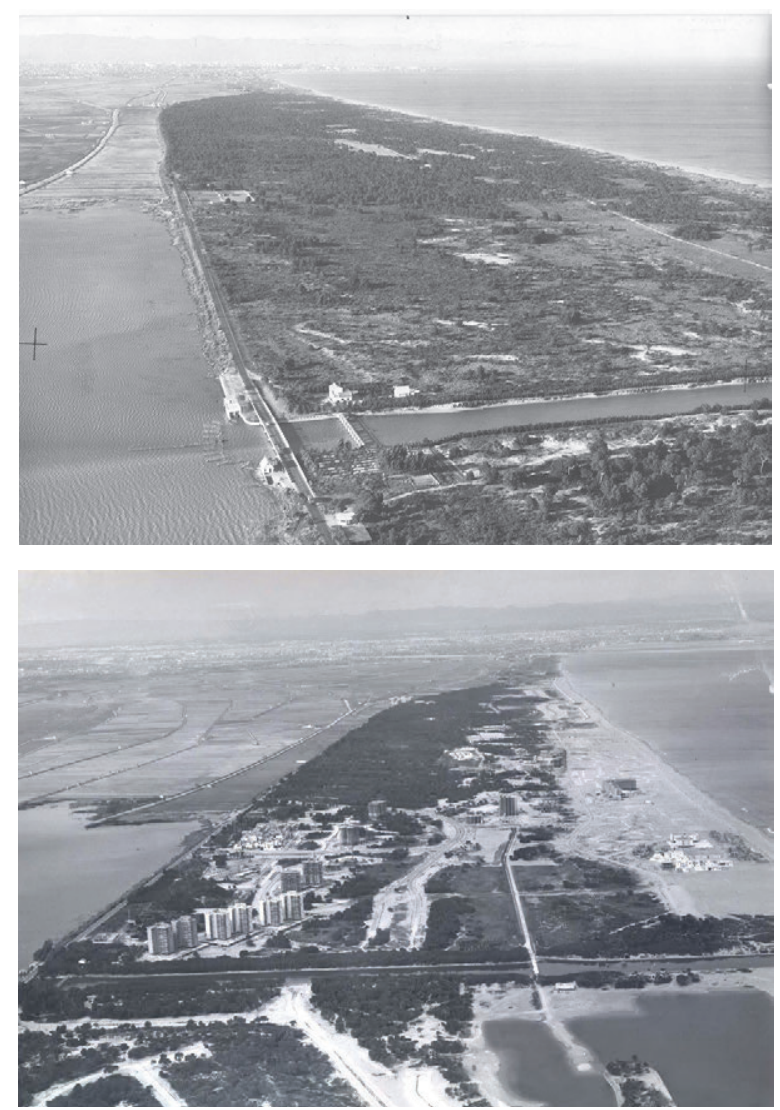

Autor: Oficina Tècnica Devesa-Albufera. 
constar su alarma frente "el anuncio de una serie de complejos edificables proyectados, algunos de asombrosa envergadura" en "este lugar incomparable." Liderados por el zoólogo valenciano Ignacio Docavo Alberti, presidente de la Sociedad, sostuvieron que la destrucción del paisaje diverso resultaría catastrófica para la inmensa riqueza de avifauna que anidaba en el invierno en la Dehesa y el litoral de la Albufera, que era uno de los humedales más importantes de Europa. El alcalde aceptó la oferta de los científicos de elaborar un informe investigando a fondo la forma de cuadrar el desarrollo con el valor ecológico de la zona. Después de varios años de estudios que culminaron en una conferencia internacional en 1968, los científicos recopilaron una lista de recomendaciones modestas que se consideraban compatibles con el plan existente, incluyendo la defensa del perímetro del lago, la creación de una estación biológica, la regulación de las temporadas de caza y pesca, el control de la contaminación, y la adición de un jardín botánico a los planes. El alcalde, que en ese momento ya había autorizado el comienzo de la construcción, aceptó el informe con gesto grave, agradeció a los científicos su tiempo, y procedió a ignorar todas sus sugerencias (Roca Miquel, 1968; Docavo Alberti, 1970, 26 de julio).

En los años posteriores al fracasado intento de los conservacionistas de la Real Sociedad, mientras las excavadoras y hormigoneras aplanaban las dunas y construían estacionamientos en la Dehesa, los ecologistas se unieron a la lucha. El campo de golf quemado por la Germania Socialista no fue otro que el del Parador de la Dehesa, es decir, se trataba de una protesta en contra de la expropiación de la tierra. Mientras tanto, el ingeniero y activista ecologista Guillermo Pons Ibáñez presentó al Ayuntamiento una "Oposición al Plan de Ordenación de la Dehesa, en su Totalidad" notariada, en la que condenó a la urbanización como "totalmente opuesta a los intereses turísticos, sociales, del pueblo valenciano, y una ofensa a su mentalidad." A diferencia de la Real Sociedad, las críticas de Pons Ibáñez surgieron principalmente de su preocupación por los problemas sociales y estéticos. Llamó a la expropiación de la propiedad pública "antisocial", y condenó rotundamente el uso irracional de "un Parque Natural espléndido y frondoso" para la edificación masiva, lo que estaba "destruyendo su esencia." Sin embargo, Pons Ibáñez y sus colegas reconocieron la influencia que tenían los argumentos conservacionistas en los círculos de la dictadura, sobre todo en tanto que llevaban el peso de la aprobación internacional consigo. Por lo tanto, agregó que la actividad turística en la escala prevista por la ciudad invitaría a "el oprobio de la crítica universal, considerando que: el Congreso Mundial para la Protección de las Aves [...] recomendó unánimemente, para nuestra Real Albufera, 'el más exquisito cuidado', para ser hábitat ideal y milenario en la traslación de estas aves." Las advertencias, otra vez, recibieron solo silencio por parte del Ayuntamiento ${ }^{7}$.

Los conservacionistas también continuaban con sus esfuerzos para concienciar al público sobre la destrucción ecológica en curso en la Dehesa. Miguel Gil Corell, presidente de la delegación valenciana de la SEO, escribió a Rodríguez de la Fuente y le pidió su ayuda, aunque advirtió que "luchar contra la urbanización sería atacar molinos de viento" y que lo mejor que podía esperar sería que se limitaran algunas de las características más ofensivas, tales como el número de edificios de gran altura o su proximidad a la orilla del lago (Gil Corell, 1970, p. 8). Rodríguez de la Fuente accedió y, una tarde del verano de 1970, su voz familiar resonó en las salas de estar de todo el país a través de su programa Vida Salvaje, denunciando los males de “especulación” y "modernidad” mientras la grabación enseñaba imágenes de pinos arrancados, peces moribundos, y topadoras cruzando a la Dehesa ${ }^{8}$. Se centró en el lago de la Albufera como sitio ecológico único e inmensamente rico que estaba en riesgo de desaparición por las amenazas conjuntas de la contaminación industrial y el desarrollo en la Dehesa.

Hasta este punto, el asunto de la Dehesa no había atraído la atención de la prensa local, que habitualmente había andado con cuidado en los asuntos del Ayuntamiento. Esta tendencia cambió, sin embargo, tras menos de un mes desde la emisión de Vida Salvaje, con la publicación de los primeros de una lista que llegaría a contar con más de cien artículos y editoriales en Las Provincias, el único diario independiente de Valencia, que perteneció a la familia poderosa Reyna Domènech. La figura central en este cambio fue Maria Consuelo Reyna, hija de la familia y recién nombrada subdirectora del periódico. Con su protección y bendición, durante la primera mitad de los 70, un grupo reducido de periodistas jóvenes plantearon perspectivas críticas sobre una amplia gama de temas que afectaban a la ordenación del territorio valenciano: la llegada de una inmensa fábrica de Ford en las afueras de la Albufera; la construcción de una central nuclear cercana; la construcción de carreteras; la disposición del antiguo curso del desviado río Turia. Reyna invitaba a expertos, tanto sociólogos y economistas como científicos, a contribuir con informes y reportajes a fondo en los que describían tales proyectos no solo 
como catástrofes ecológicas sino también como ataques contra la forma de vivir valenciana, que suponían la expropiación de derechos fundamentales y el empeoramiento de la calidad de vida para los trabajadores de la ciudad. Habitualmente, estos artículos integraban elementos conservacionistas y ecologistas para generar apoyo e indignación pública.

La época activista de Las Provincias, y con ella, en cierta medida, la de Valencia, empezó en 1970 con la campaña para salvar la Dehesa de El Saler (Mateu y Domínguez, 2011b). A finales de julio, el periódico publicó un editorial de Docavo Alberti, quien había aparecido en el capítulo de Vida Salvaje con Rodríguez de la Fuente como experto en el sistema biológico de la Dehesa y la Albufera, en el que criticaba la negación de la ciudad a tener en cuenta los consejos científicos. Aunque "nadie sensato puede pensar que nosotros vayamos en contra del proyecto de urbanización", insistió que "concienzudos estudios biológicos [...] son los únicos que pueden dar como fruto la salvación de la Dehesa y Albufera" (Docavo Alberti, 1970, 26 de julio). Pocos días después, el periodista Francisco Pérez Puche visitó la Dehesa y publicó un resumen de sus impresiones en el que describió el estado deteriorado de un paisaje tan querido por los valencianos. Donde durante años las familias habían acudido al bosque y la playa, escribió, ahora murallas y vallas cortaban el acceso. El paseo marítimo que se había construido sobre las dunas aplanadas ya se desmoronó por los vientos salados; los pocos parches remanentes del bosque estaban enfermos y moribundos; y el área pública minúscula sufrió de una falta deprimente de instalaciones (Pérez Puche, 1970, 17 de julio; Pérez Puche, 1970, 29 de julio).

Estas quejas tenían eco en las páginas de la revista Triunfo. En un reportaje del mismo verano de 1970, Triunfo habló con la gente de los pueblos de la zona, concluyendo que "las preocupaciones de Adena pertenecen a otro nivel cultural." Por lo tanto, recomendaron que "a la declarada polémica entre naturalistas y defensores del proyecto municipal, se una de inmediato el análisis social y político del proyecto, para conciliar [...] no solo Naturaleza y turismo [...] sino reforma y beneficio comunal [...] Es necesario un análisis social del proyecto" (Monleón, 1970, 25 septiembre). En los años posteriores, tal análisis social se publicaba en Las Provincias. Entre 1970 y 1974, este periódico publicó casi doscientos artículos y fotografías de El Saler, que incluían no solo entrevistas y editoriales de científicos prominentes, sino también los análisis sociológicos y económicos de los miembros de las facultades de la Universidad local, junto con informes de investigación a fondo en los que Puche, Reyna, y otros, acusaban al Ayuntamiento de corrupción política, gestión irresponsable, y expropiación de bienes públicos (Pérez Puche, 1970, 17 de julio; Pérez Puche, 1970, 29 de julio). La cobertura del asunto en Las Provincias fue más completa a partir de 1973, cuando Consuelo Reyna se involucró más profundamente y convirtió esto en su tema predilecto. Enfurecida por la declaración del teniente de alcalde que era ponente de la Dehesa cuando dijo que "al Saler iban cuatro señoritos y ahora lo vamos a poner a disposición de los valencianos," escribió un editorial en el que atacó al Ayuntamiento de una manera que puso en relieve los asuntos más profundos de la polémica de la urbanización (Pérez Puche, 1973, 25 de febrero).

\footnotetext{
"Entre los cuatro señoritos que iban al Saler estaba media Valencia, o tal vez Valencia entera. 'Señoritos' son los componentes de una familia que iba a pasar allí el domingo. 'Señoritos' son los que, por razones de trabajo, se veían obligados a pasar el verano en Valencia y hacían una escapada a tomar el baño al Saler. 'Señoritos' son los que, por no poderse pasar un veraneo en cualquier punta de la costa, iban todas las mañanas al Saler. Total, cuatro señoritos." (Reyna, 1973).
}

Carteles y pegatinas fijadas a los coches "de los muy valientes" ${ }^{\prime \prime}$, representaban un puño agarrando el tronco de un árbol, con el lema de "El Saler para el pueblo" o, más usual, "El Saler per al Poble", el lema adoptado por los activistas. "El Pueblo", por supuesto, quería decir la gente trabajadora de Valencia, cuyos derechos privados y culturales habían sido comprometidos por el régimen. "No se trata de reivindicar El Saler por la sola razón de que era de propiedad pública y debe volver a serlo," insistió un folleto de AEORMA, repartido por la calle. "Tampoco se trata, solamente, de que nos gustan los árboles y queremos defenderlos. Lo que se plantea es la función social que ha de cumplir la naturaleza [...] Necesitamos de El Saler [...] porque el pueblo trabajador tiene derecho, después de agotadoras jornadas de trabajo, al descanso y al contacto con la naturaleza" (La portada del almanaque de Las Provincias en 1974 demuestra la centralidad del asunto de la Dehesa en el periódico $)^{10}$.

Sin elecciones, votación, o libertad de expresión, es difícil saber con precisión cómo fue la opinión pública de los valencianos sobre el asunto de El Saler. Si dependemos solamente de lo que reflejan los archivos escritos, parece que la ciudad entera se movilizó en contra de la urbanización. En una exposición en la Facultad de Arquitectura, AEORMA describió El Saler 
como "un simbol de la lluíta pel descans de la població treballadora, dels qui no poden comprar-se una parcel.la" (Asociación Española para la Ordenación del Medio Ambiente, 1974).

Denuncias formales, impugnaciones publicadas fielmente en Las Provincias, y docenas de informes, entrevistas y fotos en las mismas páginas, repetidamente describían la indignación popular con la expropiación del parque y el consecuente deterioro ecológico. En 1972, Pons Ibáñez presentó una serie de denuncias formales a lo largo de los años en las que aseguraba que "mi más airada protesta [...] refleja el sentir de todo el Pueblo Valenciano" y produjo un pliego notariado en el que describió unos cuantos letreros de protesta escritos en las paredes de varios edificios de la ciudad: "no especuleu amb el Saler - Lladres", "Saler es del poble", "no faran platjes privades al Saler"11. Durante el verano de 1973, el periódico publicó un torrente casi continuo de cartas, entrevistas, reportajes e informes sobre el tema, casi unánimemente opuestos a la urbanización.

Aunque por lo visto Valencia entera se movilizó en defensa de El Saler, en la campaña de Valencia en la primera mitad de los $70-y$, por cierto, en las campañas ecologistas en general - tomaron parte casi exclusivamente las élites intelectuales. Quizás el conservacionismo fue territorio de científicos y "cazadores de mariposas", pero igualmente el ecologismo, su pretendido populismo no obstante, fue dominio de arquitectos y profesores de sociología. Puche compara la campaña de Las Provincias entre 1973 y 1974 a la orden apócrifa de William Randolph Hearst a su corresponsal en la Habana: "usted ponga las crónicas, que yo pondré la guerra con España." Según Puche y Móstoles, los activistas progresistas - los de AEORMA y otros grupos izquierdistas, incluyendo al PCE - "ponían a la gente, la movilización," mientras Las Provincias "ponía la música, la ambientación orquestal necesaria. Porque lo que contaba era ir minando el sistema del franquismo en un grado de colaboración que por aquellos días fue bastante acentuado." Pons Ibáñez, Marqués, y otros intelectuales hacían "solo lo suficiente" para dar a los periodistas algo que escribir, y los colegas del periódico "magnificaron todo" con el fin de crear la ilusión de consenso popular ${ }^{12}$. "Si una persona se fue a la Dehesa" para manifestarse en contra de las condiciones allí, confirma Consuelo Reyna, "apareció en el periódico como si se tratara de cien." ${ }^{13}$ Lo mismo hacían con unas pocas cartas escritas al editor, haciendo que pareciera una oleada de apoyo. Solo a finales de la campaña, en agosto de
1974, empezaron a aparecer escritos firmados por varias asociaciones de vecinos en las páginas del periódico, e incluso entonces no había muchos. La única movilización pública ocurrió en el otoño de 1974, cuando más de doscientas personas respondieron a una llamada de AEORMA para acercarse a la playa de El Saler e intentar, sin éxito, plantar una bandera valenciana en la arena. ${ }^{14}$

Del mismo modo que el periódico proveía una tapadera de apoyo popular para los activistas anti-franquistas, en alguna medida el movimiento anti-desarroIlista fue tapadera para la insatisfacción generalizada de progresistas sociales de cierto estatus social. Según Joaquín Fernández, escribiendo sobre una tendencia nacional, "el ecologismo era una posibilidad novedosa en la lucha contra el sistema que debía ser analizada desde la óptica globalizadora de un partido", sobre todo por parte de las élites intelectuales de las facultades universitarias del país (Fernández, 1999). Hoy en día, Consuelo Reyna dice que la motivación principal era una preocupación genuina por la desaparición de los ecosistemas únicos de la Dehesa. Insiste en que la zona representaba "el último auténtico bosque Mediterráneo" que no había sido alterado "por mano de hombre", y que, por lo tanto, esto justificaba su preservación y protección contra el desarrollo ${ }^{15}$. En sus artículos sobre la Dehesa, sin embargo, no se refería a los aspectos ecológicos sino a corrientes populistas y prodemocráticas, las cuales resonaban con un amplio público progresista. Además, aunque seguía estando involucrada en asuntos relacionados con la calidad de vida urbana, Consuelo Reyna no retomó ningún otro asunto de protección de la naturaleza, lo que sugiere una posible superficialidad de interés en el tema. Tampoco fue la única de los partidarios en contra de la urbanización a quien faltó compromiso con el movimiento ecologista: a pesar de su uso frecuente de imágenes y descripciones de pinos muertos y dunas devastadas, en 2012, Puche admitió abiertamente que los aspectos ecológicos de la campaña eran una tapadera para sus ideas políticas. Él y Móstoles se describen, a ellos mismos y a los demás periodistas y activistas de la Dehesa, como "izquierdistas vestidos de verde" que utilizaban la retórica y legitimidad de los conservacionistas como tapadera para una agenda bastante más amplia.

Es cierto que, de alguna manera, la tolerancia institucional hacia el conservacionismo y las asociaciones de vecinos prestó a los periodistas un lenguaje para expresar sus quejas políticas con seguridad. Sin embargo, el medio ambiente también importaba en sí 
mismo por razones que iban más allá de la retórica ${ }^{16}$. La preocupación sobre los paisajes locales y el control local sobre su manejo y ordenación no era única en Valencia. El tema se repetía a lo largo del movimiento anti-régimen de todo el país, vinculado a los movimientos de identidad y de autonomía regional. La vinculación de proyectos de desarrollo con la agenda centralista y el borrado de diferencias e identidades regionales hizo que el control sobre la ordenación del suelo adquiriese una importancia magnificada. Defender un paisaje local, sobre todo uno de historia culturalmente relevante como la Albufera y su Dehesa, significaba también defender el derecho de la gente local a hacerse cargo de sus propios recursos y tierras, en contra de los intereses de Madrid. El desarrollo de El Saler, diseñado por corporaciones y arquitectos madrileños, y llevado a cabo por un acuerdo entre el Ayuntamiento franquista y los ministros del régimen, fue ejemplo y encarnación de la apropiación de la riqueza natural de la Comunidad Valenciana para beneficiar un sistema elitista, corrupto e inmanentemente capitalista. Entender la movilización de "El Saler per al Poble" de esta manera también aclara el nexo entre el regionalismo y la protección del medio ambiente, común a muchos ecologistas de toda España. En Valencia, aunque Las Provincias seguía publicando en castellano, los periodistas mantuvieron un tono francamente econacionalista a lo largo de la campaña.

Con esa excepción, la campaña en contra del desarrollo de El Saler parece haber venido o de los pocos intelectuales elitistas de la Universidad o de los propios periodistas. La opinión pública, al contrario, se mantenía a favor de algún tipo de desarrollo, aunque algo menos ambicioso que el plan de la ciudad. La mayoría de los activistas están de acuerdo con la declaración de Móstoles de que "la gran mayoría [de los valencianos] quería urbanización, hotel, turismo, desarrollo, y poder irse a una playa en condiciones, como pasaba en toda España." Los planes de la ciudad eran claramente "excesivos," pero no hay evidencia de que la vehemencia con que Las Provincias se opuso al proyecto fuera compartida por el público en general ${ }^{17}$.

En ese momento, sin embargo, poco importaba. Con la salud de Franco en la decadencia final, órdenes directas de Madrid instruyeron al nuevo alcalde de Valencia para buscar un compromiso y la conciliación con las fuerzas de la oposición y, sobre todo, mantener la paz. Gracias a la campaña de Las Provincias, la urbanización encabezó la lista de la Administración valenciana de los puntos conflictivos en los que tendría que hacer concesiones con el fin de evitar que los jóvenes activistas sa- lieran a la calle. Miguel Ramón Izquierdo, un respetado y prominente abogado académico, sustituyó al anterior alcalde en el otoño de 1973 e impuso de inmediato una moratoria en la construcción. Mediante varias medidas legales y burocráticas, detuvo a los inversores y constructores durante años, hasta que asumió el poder el primer gobierno democrático de la ciudad en 1981. Irónicamente, ni los científicos conservadores ni los ecologistas marxistas Ilegaron a salvar El Saler para el pueblo, sino más bien el último alcalde franquista.

Hasta cierto punto, en 1974, la campaña de El Saler ya no trataba de El Saler como lugar físico, sino de un enfrentamiento entre dos visiones muy diferentes del futuro político de España. Sin embargo, no es casualidad que los grupos anti-franquistas de Valencia y otras partes de España incluyesen un componente ecológico importante. La campaña de El Saler ofrece una perspectiva nueva sobre el enrevesado mundo social y político del activismo en la época tardofranquista, y específicamente sobre la estrecha relación entre paisaje y poder. Representa, en cierta medida, una visión holística en la que el cambio social ocurría a través de imaginaciones ambientales. El nuevo ecologismo contrastaba con la perspectiva más compartimentada de los conservacionistas científicos que habían dominado las campañas anteriores. En la Transición, la ecología llegó a ser inseparable de la identidad regional y la política de izquierda, y los "econacionalistas" de Valencia y otras provincias periféricas se aliaban con las feministas, sindicalistas y emisoras de radio radicales. La importancia de la recuperación y la redefinición de las tierras regionales formaba así un elemento central en el resurgimiento de la democracia en España y otorgó importancia especial a los movimientos ecologistas de la época.

La diversidad del movimiento ambiental contemporáneo refleja sus raíces diversas, que incluían conservacionistas tradicionales, activistas radicales de "verde profundo" y, quizás sobre todo en el caso español, una pluralidad de "ecologistas sociales" que perseguían cambios ambientales como parte de una agenda más amplia de justicia y trasformación social. A través de la perspectiva prestada por esta definición aumentada, muchas de las movilizaciones ciudadanas de la era tardofranquista asumen matices medioambientales. Igualmente, campañas como la de El Saler, que han sido vistas históricamente como "ecologistas," se pueden entender ahora como amalgamas de varios objetivos sociales y políticos cuyas conexiones a paisajes y ecosistemas físicos eran más tenues de lo que se creía. 


\section{NOTAS}

1. Para una discusión más profunda sobre la influencia política de los científicos a nivel mundial en los sesenta, véase Goodell (1975).

2. Entrevista a Vicente González Móstoles (Valencia, 26 abril 2012); Josep-Vicent Marqués, documentos relacionados con AEORMA de diciembre 1974, colección privada de Miguel Ramón Izquierdo.

3. Entrevista a Vicente Ramón Quirós, Miguel Ramón Quirós y Francisco Pérez Puche (Valencia, 2 mayo 2012) y entrevista a Maria Consuelo Reyna (Valencia, 1 mayo 2012).

4. Entrevistas a Vicente González Móstoles (Valencia, 26 abril 2012) y a Francisco Pérez Puche (Valencia, 12 abril 2012).

5. Ayuntamiento de Valencia, folleto propagandista para el Plan General de Ordenacion del Monte de la Dehesa, 13 diciembre 1963, Servicio de Planeamiento del Ayuntamiento de Valencia (en adelante SP); Ayuntamiento de Valencia, Urbanización del Monte de la Dehesa, Oferta de TEVASA, Annex 3: Referencias Tecnicas y Financieras, diciembre 1966, SP.

6. Real Sociedad Española de Historia Natural, informe sobre el valor histórico natural de la Albufera, dirigido al Ayuntamiento de Valencia, 22 marzo 1964, SP.

7. Guillermo Pons Ibáñez, Oposición al Plan de Ordenación de la Dehesa, en su totalidad, entregado al Ayuntamiento de Valencia, 3 febrero 1970, Colección privada de María Consuelo Reyna (en adelante MCR).

\section{BIBLIOGRAFÍA}

Asociación Española para la Ordenación del Medio Ambiente (AEORMA) (1974). El Saler per al Poble: Datos para una decisión colectiva. Valencia.

Alonso-Geta, M. E. (1962). La administración, punto de equilibrio entre el cazador y la caza. Montes, 107, pp. 403-409.

Anónimo (1974, 29 de junio) La Asociación de cabezas de familia de la Dehesa impugna el proyecto de la remodelación. Las Provincias, p. 15

Anónimo (1974, 30 de junio). Dos nuevas alegaciones contra la remodelación de la Dehesa. Las Provincias, p. 20.

Anónimo (1974, 21 de julio). AEORMA se adhiere a la impugnación colectiva sobre El Saler. Las Provincias, p. 20.

Araújo, J. (1990). Félix Rodríguez de la Fuente: la voz de la naturaleza. Barcelona: Salvat.

Barber, S. (1974, 27 de junio). Guillermo Pons Ibáñez: El Ecosistema del Saler y la Dehesa, único en el mundo, habría que dejarlo como estaba. Las Provincias, p. 12.

Bellveser, R. (1974, 29 de junio). El Saler: Datos para una decisión colectiva. Las Provincias, pp. 5-6.

Bellveser, R. (1974, 16 de julio). Los que visitan la exposición sobre El Saler: casi total unanimidad, hay que salvarlo como sea. Las Provincias, pp. 3-4.

Berenguer, R. (1964, 17 de enero). Notas al margen de un proyecto magno. Valencia Atracción, 348, p. 17.

Bess, M. (2003). The Light-Green Society: Ecology and Technological Modernity in France, 1960-2000. Chicago: University of Chicago Press.
8. Vida Salvaje, emisión original 30 junio 1970.

9. Entrevista a Vicente González Móstoles (Valencia, 26 abril de 2012).

10. AEORMA, Al Pueblo Valenciano, septiembre 1974, MCR.

11. Guillermo Pons Ibáñez, Parcelación y Venta del Monte de la Dehesa, al Ayuntamiento de Valencia, 24 abril 1972, MCR; pliego notariado por Rafael Azpitarte Camy, Notario de Valencia, 4 julio 1972, MCR.

12. Comunicación personal de Francisco Pérez Puche (correo electrónico de 21 enero de 2012).

13. Entrevista a Maria Consuelo Reyna (Valencia, 1 mayo 2012).

14. AEORMA, Al Pueblo Valenciano, septiembre 1974, MCR; Comisiones de Barrio y Pueblo de Valencia, Grupos de Amigos del Saler, Vecinos, Pueblo, Trabajadores de Valencia, Septiembre 1974, MCR.

15. Entrevista a Maria Consuelo Reyna, (Valencia, 1 mayo 2012).

16. Entrevista a Francisco Pérez Puche (12 abril 2012) y comunicación personal del mismo autor (correo electrónico de 21 enero de 2012).

17. Comunicación personal de Francisco Pérez Puche (correo electrónico de 21 enero de 2012).

Costa Morata, P. (2011). Ecologíada (100 batallas). Madrid: Editorial Biblioteca Nueva.

Docavo Alberti, I. (1970, 26 de julio). La verdad sobre el asunto Dehesa-Albufera. Las Provincias, p. 16.

Dolç, C. (2011). Entrevista. Revista Seducción Ambiental, 2, pp. 10-12.

Farias Barona, J. (1942). Hojas Divulgadoras: Riqueza de nuestros ríos. El Nansa, en Santander. Madrid: Ministerio de Agricultura.

Fernández, J. (1999). El ecologismo español. Madrid: Alianza.

García, S. (1995). Urban Communities and Local Participation in Spain. Annals of the American Academy of Political and Social Science, 540 (1), pp. 63-76. http://dx.doi. org/10.1177/0002716295540000006

Gil Corell, M. (1970). Informe a Adena de la Sociedad Española de Ornitología. Trofeo, I, pp. 6-13.

Girona, M. (1974, 19 de junio). El Saler a encuesta (2): Se debería tender a la recuperación al máximo y a la conservación de las mejores condiciones de un parque público absolutamente necesario. Las Provincias, p. 5.

Goodell, R. (1975). The Visible Scientists. Boston: Little, Brown and Co.

Gottlieb, R. (2005). Forcing the Spring: The Transformation of the American Environmental Movement (revised edition). Washington: Island Press.

Havel, V. y Keane, J. (1985). The Power of the Powerless: Citizens against the state in central-eastern Europe. Armonk, NY: M. E. Sharpe. 
Hays, S. (1959). Conservation and the Gospel of Efficiency: The Progressive Conservation Movement, 1890-1920. Cambridge: Harvard University Press.

Iglesias, C. (1970). Más sobre la Albufera. España Económica, 3691, p. 15.

Marqués, J. V. (1980). Ecología y lucha de clases. Madrid: Ediciones Zero.

Mateu, A. y Domínguez, M. (2011a). Quan el Saler tornà al poble. Métode, 70, pp. 42-47.

Mateu, A. y Domínguez, M. (2011b). Inicios del columnismo ambiental en la prensa española: la campaña de Las Provincias sobre la urbanización de El Saler (Valencia, España). Zer, 16 (30), pp. 171-187.

Monleón, J. (1970, 25 septiembre) Informe sobre una polémica: El Saler y la Albufera. Triunfo, 25, pp. 15-18.

Ortega, M. (1974, 27 de julio). Crónica de Valencia: El Saler, para el Pueblo. El Mundo.

Pérez Puche, F. (1970, 17 de julio). ¿Hacía la urbanización definitiva de La Dehesa? Las Provincias, p. 13

Pérez Puche, F. (1970, 29 de julio). El bañista paga las consecuencias del 'verano negro' de El Saler. Las Provincias, p. 15.

Pérez Puche, F. (1973, 25 de febrero). La urbanización de la Dehesa, al día. Las Provincias, pp. 41-42 y p. 67.

Radcliff, P. (2011). Making Democratic Citizens in Spain: Civil Society and the Popular Origins of the Transition, 1960-78. New York: Palgrave Macmillan. http://dx.doi.org/10.1057/9780230302136

Reyna, M. C. (1973, 10 de mayo). La Devesa (2): la 'reserva' para los valencianos. Las Provincias, p. 5.

Roca Miquel. R. (1968). Avifauna cinegética: la portentosa Albufera de Valencia. Valencia Atracción, p. 404.
Simó, T. (1974, 18 de junio). Más claridad en la exposición de la última remodelación de El Saler. Las Provincias, p. 5.

Taylor, D. (2009). The Environment and the People in American Cities, 1600s-1900s. Durham, NC: Duke University Press. http:// dx.doi.org/10.1215/9780822392248

Valverde, J. A. (1975). Doñana y las marismas del Guadalquivir: su rescate y sus problemas presentes y futuros. En: Bernís, F. (dir.), Fernández Cruz, M., Maluquer, S. y Sáez Royuela, R. (eds.). Ornitología y conservación de la naturaleza hoy. Homenaje al Dr. José A. Valverde Gómez. Madrid: Ministerio de Educación y Ciencia, pp. 25-56.

Ventura, V. (1970). La Dehesa del Saler. España Económica, 3692, pp. 13-14.

Weiner, D. (1999). A Little Corner of Freedom: Russian Nature Protection from Stalin to Gorbachëv. Berkeley: University of California Press.

\section{Textos legales}

Ley cediendo en propiedad al Ayuntamiento de Valencia el lago denominado La Albufera y el monte denominado Dehesa de La Albufera. Gaceta de Madrid, 25 de junio de 1911, p. 848.

\section{Recursos de Internet}

Amer, E. (2008). Recordatori a Josep Vicent Marqués, Primers anys de l'ecologisme valencià (1) [en línea]. [Fecha de consulta: 25 de noviembre de 2014]. Disponible en: http://www.accioecologista-agro.org/spip.php?article224

Federación del Movimiento Ecologista. La Propuesta de Daimiel. 3 a Asamblea del Movimiento Ecologista, 22-25 julio 1978. Disponible en http://grupostirner.blogspot.com.es/2014/01/propuesta-de-daimiel-1978.html 